\title{
Andrographolide induces apoptotic and non-apoptotic death and enhances tumor necrosis factor-related apoptosis-inducing ligand-mediated apoptosis in gastric cancer cells
}

\author{
SUNG-CHUL LIM ${ }^{1}$, HO JONG JEON ${ }^{1}$, KEUN HONG KEE ${ }^{1}$, MI JA LEE ${ }^{1}$, RAN HONG ${ }^{1}$ and SONG IY HAN ${ }^{2}$ \\ ${ }^{1}$ Department of Pathology; ${ }^{2}$ Division of Premedical Science, College of Medicine, \\ Chosun University, Gwangju 61452, Republic of Korea
}

Received February 26, 2016; Accepted February 27, 2017

DOI: $10.3892 / 01.2017 .5923$

\begin{abstract}
Andrographolide, a natural compound isolated from Andrographis paniculata, has been reported to possess antitumor activity. In the present study, the effect of andrographolide in human gastric cancer (GC) cells was investigated. Andrographolide induced cell death with apoptotic and non-apoptotic features. At a low concentration, andrographolide potentiated apoptosis and reduction of clonogenicity triggered by recombinant human tumor necrosis factor-related apoptosis-inducing ligand (rhTRAIL). Exposure of GC cells to andrographolide altered the expression level of several growth-inhibiting and apoptosis-regulating proteins, including death receptors. It was demonstrated that activity of the TRAIL-R2 (DR5) pathway was critical in the development of andrographolide-mediated rhTRAIL sensitization, since its inhibition significantly reduced the extent of apoptosis induced by the combination of rhTRAIL and andrographolide. In addition, andrographolide increased reactive oxygen species (ROS) generation in a dose-dependent manner. N-acetyl cysteine prevented andrographolide-mediated DR5 induction and the apoptotic effect induced by the combination of rhTRAIL and andrographolide. Collectively, the present study demonstrated that andrographolide enhances TRAIL-induced apoptosis through induction of DR5 expression. This effect appears to involve ROS generation in GCs.
\end{abstract}

\section{Introduction}

Gastric cancer (GC) is one of the most common types of malignancy and is the leading cause of cancer-associated mortality worldwide (1). A large number of chemotherapy drugs have

Correspondence to: Professor Song Iy Han, Division of Premedical Science, College of Medicine, Chosun University, 309 Pilmun-daero, Gwangju 61452, Republic of Korea

E-mail: sihan@chosun.ac.kr

Key words: andrographolide, gastric cancer, tumor necrosis factor-related apoptosis-inducing ligand, apoptosis been tested for patients with advanced gastric cancer, and considerable progress has been achieved with platinum drug-based regimens (2). However, the overall prognosis of GC remains poor (3). Therefore, additional efforts are ongoing to develop safer and more effective therapeutic strategies.

Tumor necrosis factor-related apoptosis-inducing ligand (TRAIL) has emerged as an attractive anticancer agent, since it selectively induces cell death in various human cancer cells with little effect on normal cells (4). Thus far, five TRAIL receptors have been identified in humans. Among them, TRAIL-R1 (DR4) and TRAIL-R2 (DR5) mediate apoptosis through characteristic interactions of their cytoplasmic death domains (5). Engaged TRAIL receptors recruit adaptor proteins and form the death-inducing signaling complex, which subsequently activates caspase cascades with or without mitochondrial amplification (6). However, it has also been shown that numerous TRAIL-resistant cancer cells exist (7). Therefore, a number of approaches, such as combined administration of TRAIL with various sensitizers, including synthetic small molecules, natural compounds and enzyme inhibitors, are currently being tested in attempt to overcome TRAIL resistance (8-10).

The diterpenoid lactone andrographolide is one of the biologically active constituents of Andrographis paniculata, a medicinal plant traditionally used for prevention and treatment of various diseases (11-13). A number of studies have demonstrated that andrographolide and its analogues possess potential anti-inflammatory and antitumor effects mediated by attenuation of nuclear factor- $\kappa \mathrm{B}$ activation in various systems (11-14). Andrographolide also induces cell cycle arrest and apoptosis of cancer cells by inhibiting phosphoinositide 3-kinase/protein kinase $\mathrm{B}$, mitogen-activated protein kinase and other tumor growth pathways, depending on the type of treated cells (15-18). Andrographolide triggers intrinsic and extrinsic apoptotic pathways in different cancer cells via mechanisms involving activation of p53, reactive oxygen species (ROS) and topoisomerase II $(17,19,20)$. Furthermore, andrographolide demonstrated a potent anticancer effect when it was applied in combination with other anticancer agents, including cisplatin and doxorubicin $(21,22)$. In the present study, the effect of andrographolide was determined in GCs, and it was reported to perform as a GC sensitizer to the action of TRAIL. 


\section{Materials and methods}

Cell culture and dosing. The human GC SNU601, SNU638 and AGS cell lines were obtained from the Korean Cell Line Bank (Seoul, Korea) and cultured for 2-10 weeks in the Roswell Park Memorial Institute-1640 medium (Invitrogen; Thermo Fisher Scientific, Inc., Waltham, MA, USA) supplemented with $10 \%$ (v/v) fetal bovine serum (PAA Laboratories; GE Healthcare, Chalfont, UK) and 1\% Penicillin-Streptomycin (Welgene, Inc., Gyeongsan, Korea) at $37^{\circ} \mathrm{C}$ in a $5 \% \mathrm{CO}_{2}$ atmosphere. Drug treatment of the cells was performed by adding 0-50 $\mu \mathrm{M}$ andrographolide (Sigma-Aldrich; Merck KGaA, Darmstadt, Germany) alone or with $5-20 \mathrm{ng} / \mathrm{ml}$ recombinant human TRAIL (rhTRAIL; a gift from T.H. Kim, Department of Biochemistry and Molecular Biology, Chosun University, Korea) (23) to the culture medium at $37^{\circ} \mathrm{C}$ for $24-48 \mathrm{~h}$. Antioxidants $\mathrm{N}$-acetyl cysteine (NAC), butylated hydroxyanisole (BHA), Trolox and catalase, and caspase inhibitors z-DEVD, z-IETD, z-LEHD, z-LEVD and z-VAD were purchased from EMD Millipore (Billerica, MA, USA).

MTT viability assays. For the MTT assay, cells were plated in the wells of a 96-well plate at a density of $1 \times 10^{4}$ cells/well, incubated at $37^{\circ} \mathrm{C}$ for $24 \mathrm{~h}$, and then treated with $0.2 \%$ dimethyl sulfoxide as a vehicle or $10-50 \mu \mathrm{M}$ andrographolide at $37^{\circ} \mathrm{C}$ for $48 \mathrm{~h}$. The MTT solution $(0.5 \mathrm{mg} / \mathrm{ml})$ was added to the wells and incubated at $37^{\circ} \mathrm{C}$ in a $\mathrm{CO}_{2}$ incubator for the last $4 \mathrm{~h}$. The plates were centrifuged at $600 \times \mathrm{g}$ for $10 \mathrm{~min}$ at room temperature and the culture medium was removed. The cells were solubilized using $100 \mu \mathrm{l}$ of $100 \%$ dimethyl sulfoxide and the solubilized formazan product was quantified using an enzyme-linked immunosorbent assay plate reader at $595 \mathrm{~nm}$. The absorbance of the untreated cells was set as $100 \%$ and cell survival was expressed as a percentage of this value.

Hoechst 33342 (HO)/propidium iodide (PI) double staining. Treated cells were stained with $1 \mu \mathrm{g} / \mathrm{ml}$ of $\mathrm{HO}$ and $5 \mu \mathrm{g} / \mathrm{ml}$ of PI for $15 \mathrm{~min}$ at room temperature in the dark. Floating and attached cells were collected and centrifuged at $500 \times \mathrm{g}$ for $10 \mathrm{~min}$ at $4^{\circ} \mathrm{C}$. The pooled cell pellets were washed with ice-cold PBS, fixed in $3.7 \%$ formaldehyde on ice, washed twice again and resuspended with PBS, and then a fraction of the suspension was centrifuged at $500 \mathrm{x} g$ for $10 \mathrm{~min}$ at room temperature in Shandon Cytospin II (Thermo Fisher Scientific, Inc.). Slides were prepared, air dried, mounted with aqueous mounting medium (Gel Mount; Biomeda, Foster City, CA, USA) and observed under a fluorescence microscope (magnification, x200; DM5000; Leica Microsystems, GmbH, Wetzlar, Germany) at respective excitation/emission wavelengths of 340/425 nm (HO) and 580/630 nm (PI). For each slide, five fields were randomly chosen. Morphological assessments of apoptotic and non-apoptotic death were performed. Intact blue nuclei, condensed/fragmented blue nuclei, condensed/fragmented pink nuclei and intact or crushed pink nuclei were considered viable, early apoptotic, late apoptotic or non-apoptotic dead cells, respectively. A total of 500 cells distributed across random microscope viewing fields were counted and the number of apoptotic or non-apoptotic cells was expressed as a percentage of the total number of cells scored.
Immunoblotting. Protein extracts $(50 \mu \mathrm{g})$ were electrophoretically separated using 10-12\% SDS-PAGE and transferred to a nitrocellulose membrane using a standard technique (24). Antibodies specific to B-cell lymphoma-2 (Bcl-2; dilution, 1:200; catalog no., 2876S) and B-cell lymphoma-extra-large (Bcl-xL; dilution, 1:500; catalog no., 2762S) were purchased from Cell Signaling Technology, Inc. (Danvers, MA, USA). Anti-p53 (dilution, 1:1,000; catalog no., sc-126), anti-p21 (dilution, 1:1,000; catalog no., sc-6246) and anti- $\alpha$-tubulin (dilution, 1:500; catalog no., sc-32293) were obtained from Santa Cruz Biotechnology, Inc. (Dallas, TX, USA). Anti-DR4 (dilution, 1:200; catalog no., 1139) and anti-DR5 (dilution, 1:500; catalog no., 2019) were purchased from ProSci, Inc. (Poway, CA, USA). Anti-Bcl-2 associated X protein (Bax; dilution, 1:200; catalog no., BD 610983) was purchased from BD Biosciences (San Hose, CA, USA) and anti-Bcl-2 homologous antagonist/killer (Bak; dilution, 1:200; catalog no., 06-536) was purchased from EMD Millipore. Antibody signals were detected using an Image Station 4000 MM image analyzer (Kodak, Rochester, NY, USA).

RNA interference (RNAi). For the RNAi experiment, the sequences of small interfering (si)RNA were as follows: DR4 forward, 5'-CUGGAAAGUUCAUCUACUU(dtdt)-3' and reverse, 5'-AAGUAGAUGAACUUUCCAG(dtdt)-3'; DR5 forward, 5'-CAGACUUGGUGCCCUUUG(dtdt)-3' and reverse, 5'-UCAAAGGGCACCAAGUCUG(dtdt)-3'; and control siRNA forward, 5'-CCUACGCCACCAAUU UCGU(dtdt)-3 and reverse, 5'-ACGAAAUUGGUGGCG UAGG(dtdt)-3' (Bioneer Corporation, Daejeon, Korea). Cells were individually transfected with siRNA oligonucleotides using an Amaxa Transfection System ${ }^{\mathrm{TM}}$ (Basel, Switzerland) and grown at $37^{\circ} \mathrm{C}$ for $24-36 \mathrm{~h}$ prior to the drug treatment.

Clonogenic assay. Clonogenic activity was measured according to established procedures with certain modifications in cell numbers and incubation period (25). For the clonogenic assay, $2.5 \times 10^{5}$ cells $/ 35-\mathrm{mm}$ dishes were pre-incubated with andrographolide or vehicle at $37^{\circ} \mathrm{C}$ for $18 \mathrm{~h}$, followed by incubation with rhTRAIL $37^{\circ} \mathrm{C}$ for another $6 \mathrm{~h}$. Cells were then trypsinized, and counted under light microscope at $\times 100$ magnification. The mean value of the cell number from 5 counts per sample was calculated and 2,000 cells were re-plated in $60-\mathrm{mm}$ dishes in duplicate, and maintained at $37^{\circ} \mathrm{C} / 5 \% \mathrm{CO}_{2}$ for 14 days in a humidified atmosphere. The grown cells were fixed with $3.7 \%$ formaldehyde, stained with $0.5 \%$ crystal violet, and colonies ( $>0.7 \mathrm{~mm}$ diameter) were scored to determine cell proliferating ability (26).

Detection of ROS generation. Cells were treated with andrographolide for 8, 18 and $24 \mathrm{~h}$ and loaded with $50 \mu \mathrm{M} 2$ ', 7'-dichlorofluorescin diacetate (DCFDA; Molecular Probes; Thermo Fisher Scientific, Inc.) to measure ROS generation and $0.5 \mu \mathrm{g} / \mathrm{ml} \mathrm{HO}$ to quantify cell number for $30 \mathrm{~min}$. Subsequent to rinsing twice with PBS, fluorescent images were captured with an inverted fluorescence microscope (magnification, x200) or fluorescence intensities were obtained with a Fluorocount (PerkinElmer, Inc., Port Richey, NJ, USA) at excitation/emission wavelengths of 490/530 nm (DCFDA) and 
A

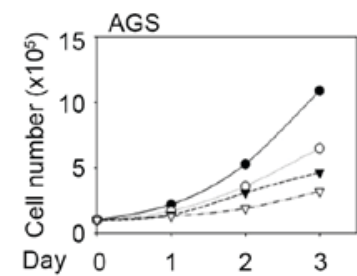

B

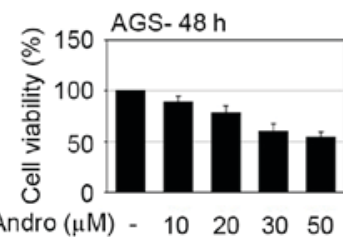

C
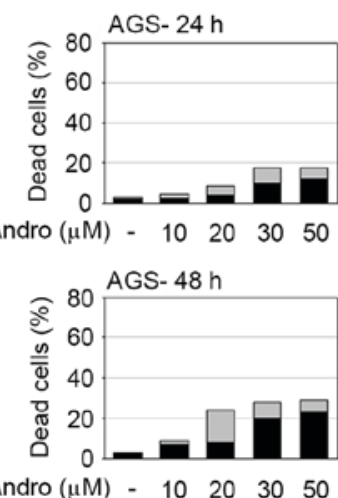
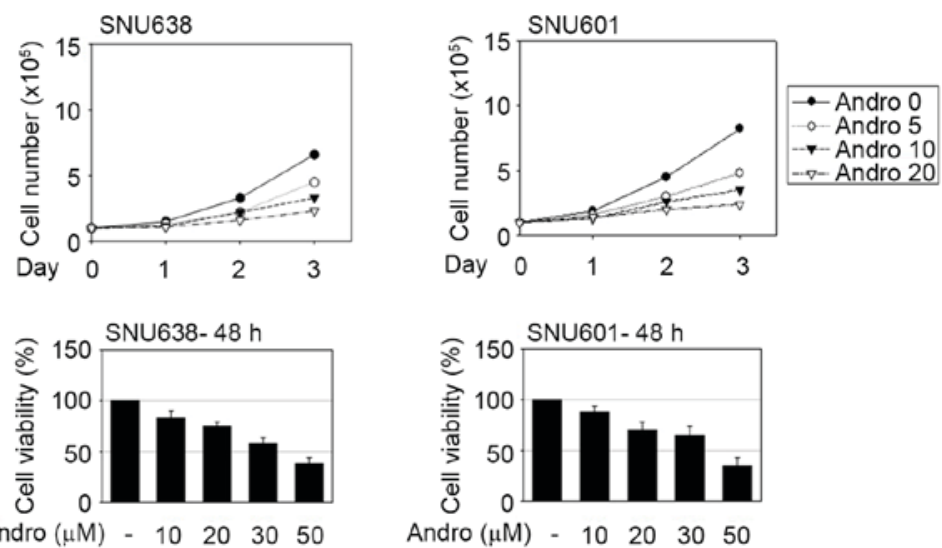

Andro $(\mu \mathrm{M})-10 \quad 20 \quad 3050$
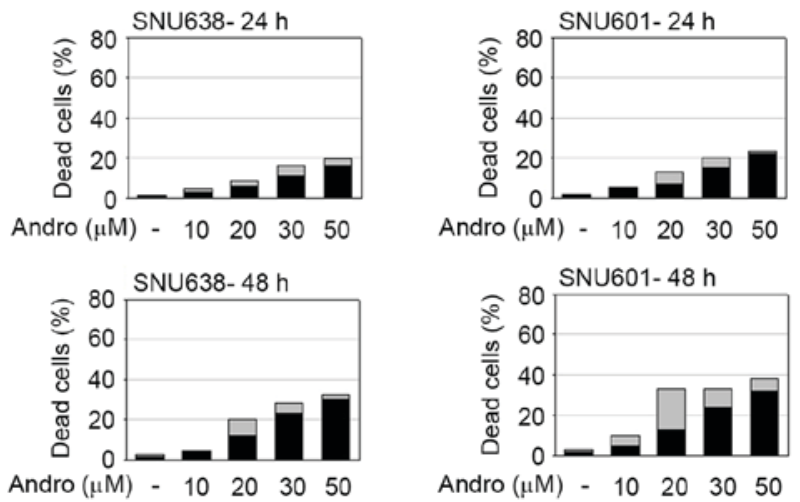

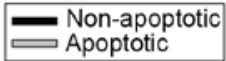

Figure 1. Andrographolide induced an antitumor effect in human GC cells. AGS, SNU638 and SNU601 cells were treated with andrographolide at the indicated concentrations for the indicated durations. Cells were then (A) counted to assess cell growth, (B) subjected to the MTT assay for measurements of cell viability or (C) stained with HO/PI for monitoring the occurrence of apoptotic and non-apoptotic cell death, as described in the materials and methods section. Andro, andrographolide.

340/425 (HO), and values of ROS production were obtained by determining the ratio of DCFDA/HO signals per well.

Statistical analysis. All numerical data are reported as the mean \pm standard error. $\mathrm{P}<0.05$ was considered to indicate a statistically significant difference. All data represent the results of $\geq 3$ independent experiments. Student's t-test was used to evaluate the differences between control and treated group values, and one-way analysis of variance was applied to analyze the significance of differences caused by the effects of gene silencing or caspase inhibition.

\section{Results and Discussion}

Andrographolide inhibits cell growth and triggers apoptotic and non-apoptotic cell death in human GC cells. To investigate the antitumor efficacy of andrographolide in GC, AGS, SNU601 and SNU638 human GC cells were treated with andrographolide at several concentrations and the effect of the compound on cell growth and cell viability was assessed by counting the number of live cells and by performing the MTT assay, respectively. Andrographolide evidently decreased the cell growth rate and viability of GC cells (Fig. 1A and B). To examine whether a decrease of cell viability was accompanied by andrographolide-induced cell death, occurrence of apoptotic and non-apoptotic cell death was detected using the $\mathrm{HO} / \mathrm{PI}$ double staining method. Apoptotic and non-apoptotic cell death was assessed by the percentage of condensed or cleaved apoptotic nuclei following HO staining (apoptotic death) and PI-stained red cells without apoptotic features (non-apoptotic death). As shown in Fig. 1C, andrographolide induced apoptotic and non-apoptotic cell death in GC cells. While the total number of dead cells was linearly associated with the concentration of andrographolide, the number of apoptotic dead cells with typical cleaved or condensed nuclei peaked in presence of $20 \mu \mathrm{M}$ andrographolide. At concentrations of andrographolide exceeding $20 \mu \mathrm{M}$, PI-stained cells with rigid shapes of nuclei became predominant, indicating an increase of andrographolide-induced non-apoptotic cell death.

Andrographolide regulates expression of intrinsic and extrinsic apoptotic proteins. To investigate the mechanisms involved in andrographolide-induced cytotoxicity, expression levels of cell cycle inhibitory proteins and apoptosis-inducing proteins were analyzed by immunoblotting assay. As shown in Fig. 2, andrographolide increased expression of cyclin inhibitor p21 in all tested GC cells and levels of the p27 protein in SNU638 cells. Andrographolide also induced expression of membrane death receptors DR4 and DR5 in GC cells. DR5 expression was induced by relatively low concentrations of andrographolide $(10-20 \mu \mathrm{M})$, whereas induction of DR4 expression was observed following exposure to increased concentrations of andrographolide (30-40 $\mu \mathrm{M})$. Andrographolide also increased p53 levels in AGS and SNU638 cells, but not in SNU601 


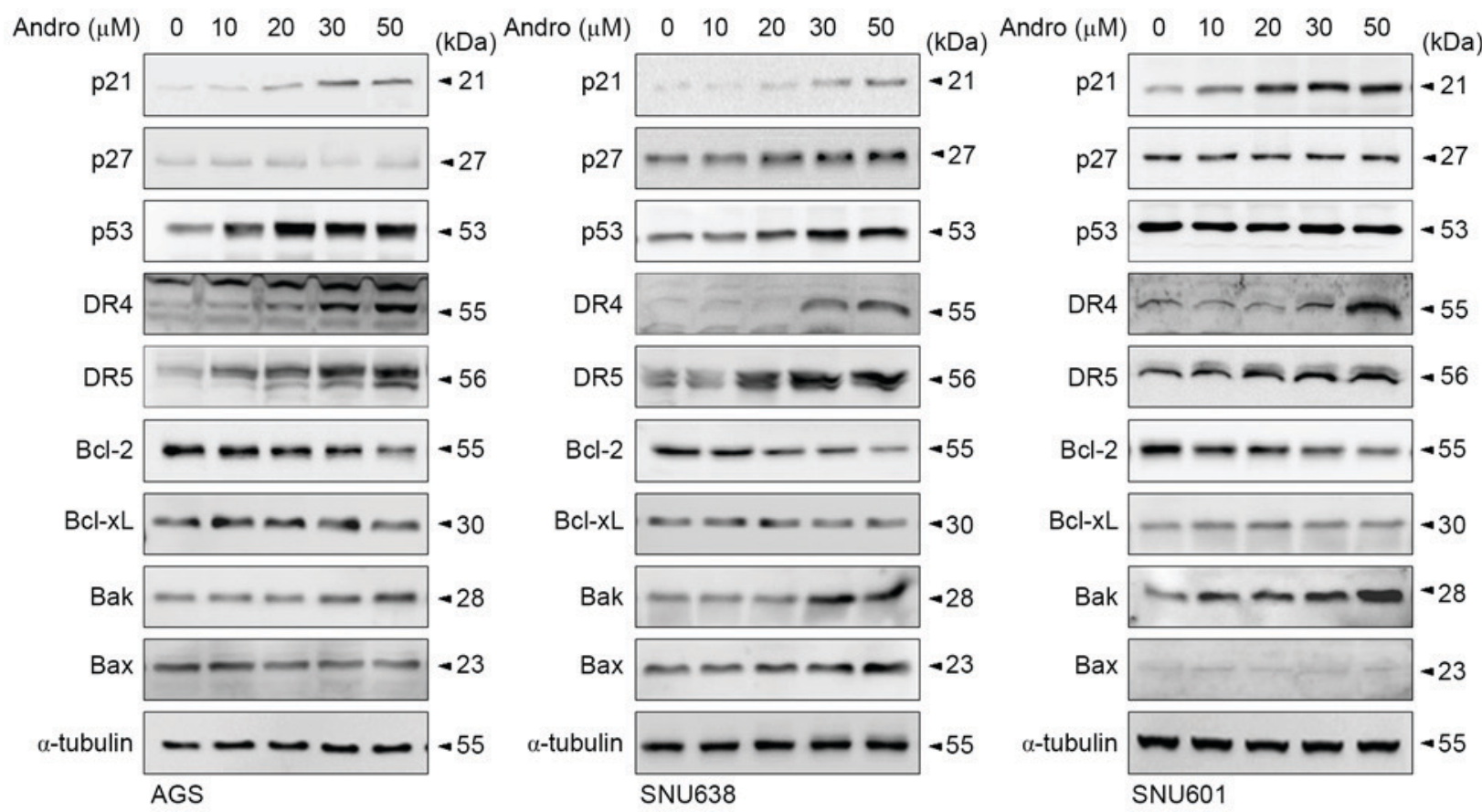

Figure 2. Andrographolide affected expression levels of various cell death-regulating proteins in human GC cells. AGS, SNU638 and SNU601 cells were incubated with andrographolide at indicated concentrations for $48 \mathrm{~h}$ and then harvested to prepare total protein lysates, in which levels of p21, p27, p53, DR4, DR5, Bcl-2, Bcl-xL, Bak and Bax proteins were determined by immunoblotting. $\alpha$-tubulin was used as a loading control. Bcl-2, B-cell lymphoma-2; Bcl-xL, B-cell lymphoma-extra-large; DR4, tumor necrosis factor-related apoptosis-inducing ligand-receptor 1; DR5, tumor necrosis factor-related apoptosis-inducing ligand-receptor 2; Bax, Bcl-2-associated X protein; Bak, Bcl-2 homologous antagonist/killer; Andro, andrographolide.

cells. The transcription factor p53 has been reported to regulate expression of p21, DR4 and DR5 in response to various cytotoxic stimuli (27-29). However, the role of p53 as a transcription regulator may not be essential in this system, since SNU638 and SNU601 cells carry transcriptionally mutant p53 protein (30). The effects of andrographolide on the expression level of Bcl-2 family members (intrinsic apoptotic regulators) was also detected. The level of anti-apoptotic Bcl-2 was inversely proportional to the concentration of andrographolide in all three GC cells, while expression of another anti-apoptotic protein, $\mathrm{Bcl}-\mathrm{xL}$, was unaffected. At high concentrations, andrographolide also affected the levels of pro-apoptotic $\mathrm{Bcl}-2$ proteins: Expression of Bak was elevated in all three GC cells tested, while the level of Bax was increased only in SNU638 cells. Based on these results, it was hypothesized that at high concentrations, andrographolide triggers various stress signaling events, including activation of the extrinsic and intrinsic apoptotic pathways in GC cells. However, although expression of pro-apoptotic proteins was directly proportional to the concentration of andrographolide, apoptotic death or total cell death was not considerably increased in the presence of high concentrations of andrographolide (Fig. 1C). This potential discrepancy may be explained by overload of apoptotic signaling under severe stress conditions: Extremely harsh stress or high doses of chemotherapeutic drugs may cause abrupt and multiple stimulation of destructive pathways as opposed to the sequential apoptotic cascades.

Andrographolide enhances rhTRAIL-induced apoptotic cell death. Although andrographolide triggered cell death of GCs and induced expression of several death-inducing proteins in the present study, the use of this drug at high doses may be unsafe due to the toxic side effects. Recently, the utility of combinations of drugs with different mechanisms of action for cancer treatment has been gaining increasing attention (31-34). Effective combinations of anticancer drugs enhance therapeutic efficacy, as well as reduce toxicity, since each constituent may be used at a lower, non-toxic dose. Thus, it was investigated whether a combination of a low concentration of andrographolide with rhTRAIL may enhance rhTRAIL-induced apoptosis of GC cells. Combined treatment was performed by a pretreatment of cell cultures with 10 or $15 \mu \mathrm{M}$ andrographolide for $24 \mathrm{~h}$, and a subsequent incubation with rhTRAIL for another $24 \mathrm{~h}$. As demonstrated in Fig. 3A, the number of apoptotic bodies was significantly increased following the combined treatment with andrographolide and rhTRAIL compared with following incubation with rhTRAIL alone. The effect of the combined treatment with andrographolide was particularly evident in AGS cells, which demonstrated resistance to rhTRAIL action. The andrographolide-mediated enhancement of the apoptotic rate was confirmed again by flow cytometric analysis, in which the increased proportion of cells in the sub- $\mathrm{G}_{1}$ area of the cell cycle was regarded as a sign of apoptosis. As shown in Fig. 3B, the combined treatment with rhTRAIL and andrographolide caused an increased number of cells in the sub- $\mathrm{G}_{1}$ phase. Subsequently, to determine whether the combined treatment with andrographolide reduced colony-forming ability of GC cells, the clonogenic assay was performed, which is based on the capacity of a single cell to proliferate into a clone. It was revealed that the combined treatment with rhTRAIL and andrographolide caused a more substantial decrease in clonogenic activity compared with the effect of rhTRAIL alone (Fig. 3C). Together, these results indicated that andrographolide promotes tumor-suppressing activity of rhTRAIL in GC cells. 
A

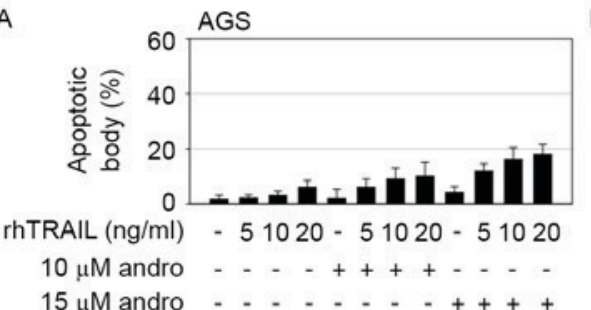

$15 \mu \mathrm{M}$ andro . . . . . . + + +

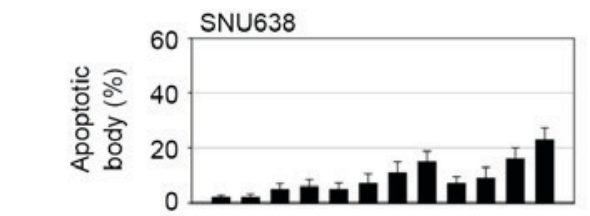

rhTRAIL $(\mathrm{ng} / \mathrm{ml})-51020-51020-51020$

$10 \mu \mathrm{M}$ andro . . . + +++ . . .

$15 \mu \mathrm{M}$ andro . . . . . + + + +

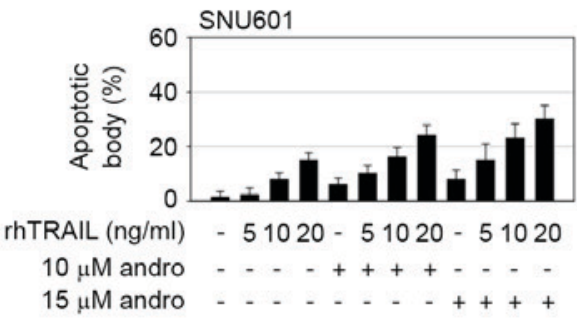

B
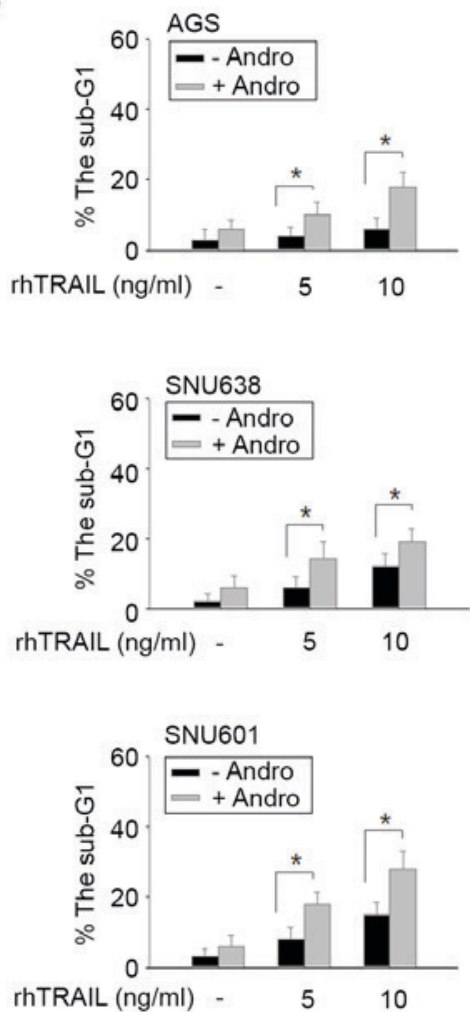

c
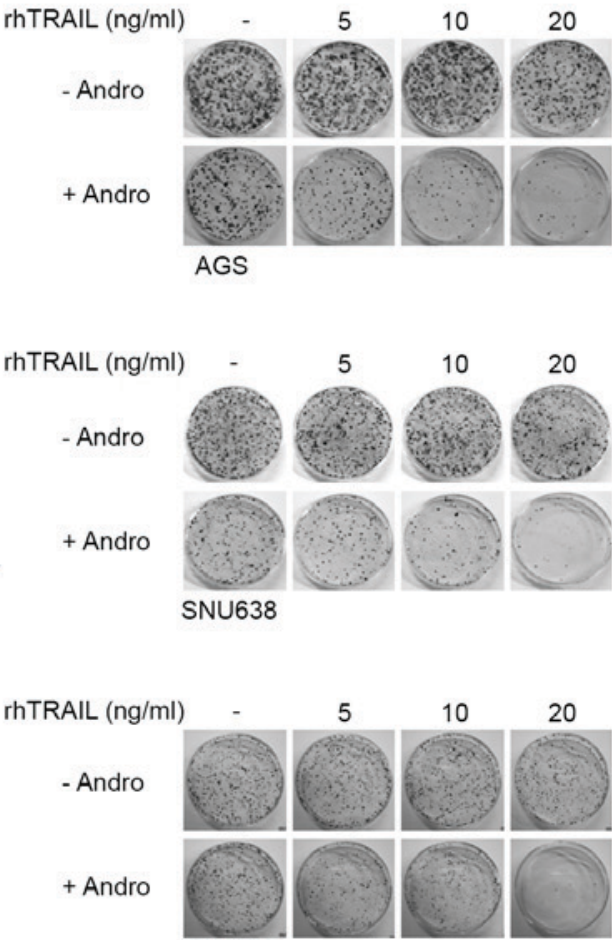

SNU601

Figure 3. Andrographolide enhanced rhTRAIL-induced apoptosis and clonogenicity. (A) Cells were pretreated with 10 or $15 \mu \mathrm{M}$ andrographolide for $24 \mathrm{~h}$ and exposed to rhTRAIL at the indicated concentration for $24 \mathrm{~h}$. Apoptosis was detected by staining cells with Hoechst 33342 and assessing the ratio of apoptotic nuclei to normal nuclei under a fluorescence microscope. (B) Cells pretreated with $15 \mu \mathrm{M}$ andrographolide for $24 \mathrm{~h}$ and exposed to rhTRAIL for $24 \mathrm{~h}$ were stained with propidium iodide and then quantified for sub- $\mathrm{G}_{1}$ DNA content by flow cytometry. " $\mathrm{P}<0.05$. (C) Cells were incubated in the absence or presence of $15 \mu \mathrm{M}$ andrographolide for $24 \mathrm{~h}$ and exposed to $0,5,10$ and $20 \mu \mathrm{M}$ rhTRAIL for the last $1 \mathrm{~h}$. Cells $(2,000)$ were then re-plated on $60-\mathrm{mm}$ dishes. Colonies were stained and counted at 2 weeks post-incubation. rhTRAIL, recombinant human tumor necrosis factor-related apoptosis-inducing ligand; Andro, andrographolide.
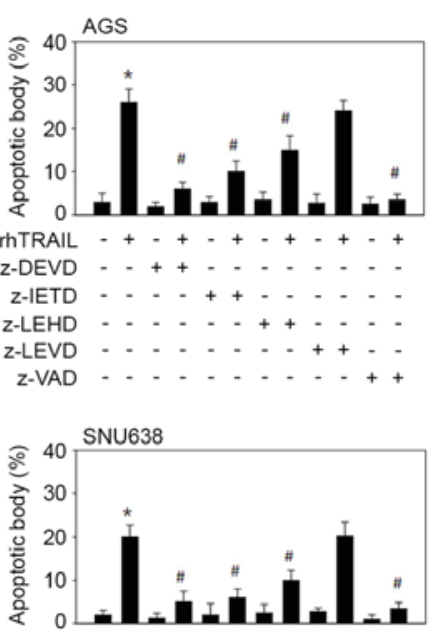

AndrotrhTRAI

Z-DEVD - . + + + . . . . . .

Z-IETD - . - + + . . .

Z-LEHD - - - - + + - - -

Z-LEVD - - - - - + + + +
B
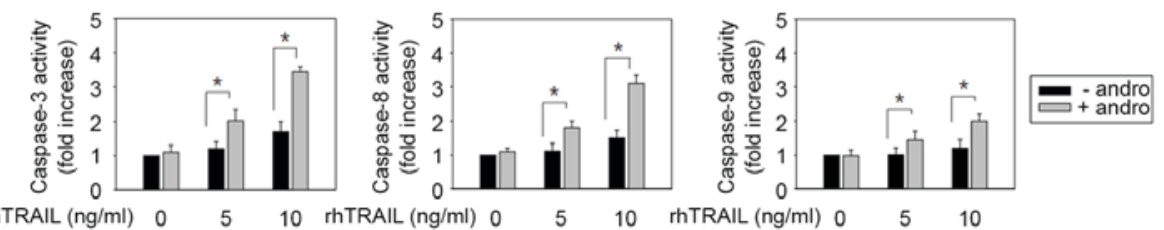

Figure 4. Apoptosis triggered by the combined action of andrographolide and rhTRAIL involves activation of caspase-3, caspase-8 and caspase-9, but not caspase-4. (A) AGS and SNU638 cells were treated with a combination of $15 \mu \mathrm{M}$ andrographolide and $10 \mathrm{ng} / \mathrm{ml} \mathrm{rhTRA}$ IL in the absence or presence of caspase-3 inhibitor z-DEVD-fmk, caspase-8 inhibitor z-IETD-fmk, caspase-9 inhibitor z-LEHD-fmk, caspase-4 inhibitor z-LEVD-fmk or pan-caspase inhibitor z-VAD-fmk for $48 \mathrm{~h}$. The treated cells were stained with Hoechst 33342 to allow detection of apoptotic cells. ${ }^{*} \mathrm{P}<0.05$ vs. control; ${ }^{\#} \mathrm{P}<0.05$ vs. andrographolide and rhTRAIL treated cells. (B) AGS cells were treated with 0,5 and $10 \mathrm{ng} / \mathrm{ml}$ rhTRAIL in the absence or presence of $15 \mu \mathrm{M}$ andrographolide and subjected into caspase activity assays. "P<0.05. (C) Cells treated with the combination of $15 \mu \mathrm{M}$ andrographolide and 10 ng/ml rhTRAIL in the absence or presence of z-DEVD, z-IETD and z-LEHD were collected for analysis of activity of different caspases. ${ }^{*} \mathrm{P}<0.05$ vs. andrographolide and rhTRAIL-treated cells. rhTRAIL, recombinant human tumor necrosis factor-related apoptosis-inducing ligand; Andro, andrographolide. 


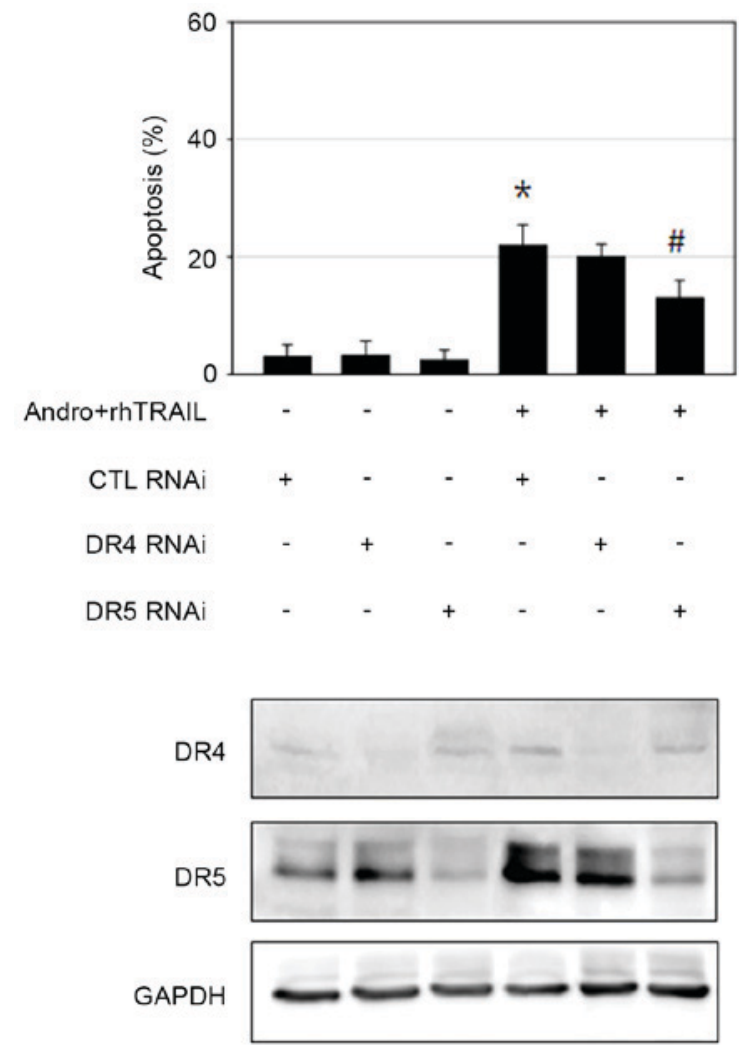

Figure 5. Andrographolide-mediated sensitization to rhTRAIL pro-apoptotic action is partially regulated by DR5. AGS cells were transfected with scrambled small interfering RNA (CTL RNAi), DR4 RNAi or DR5 RNAi and exposed to the combination of andrographolide and rhTRAIL. The treated cells were then subjected to Hoechst 33342 staining to detect apoptotic body formation by assessing the ratio of apoptotic nuclei to normal nuclei under a fluorescence microscope. ${ }^{*} \mathrm{P}<0.05$ vs. untreated CTL RNAi transfected cells; ${ }^{*} \mathrm{P}<0.05$ vs. andrographolide and rhTRAIL-treated CTL RNAi-transfected cells. Silencing effect of DR4 and DR5 was confirmed by immunoblotting. rhTRAIL, recombinant human tumor necrosis factor-related apoptosis-inducing ligand; DR4, tumor necrosis factor-related apoptosis-inducing ligand-receptor 1; DR5, tumor necrosis factor-related apoptosis-inducing ligand-receptor 2; CTL RNAi, scrambled small interfering RNA.

The effect of various caspase inhibitors on apoptosis triggered by the combination of andrographolide and rhTRAIL was then examined to estimate the signal pathways involved. As shown in Fig. 4A, the pan-caspase inhibitor z-vad-fmk and the caspase- 3 inhibitor z-DEVD-fmk almost completely prevented apoptosis. The caspase- 8 inhibitor z-IETD-fmk also significantly inhibited apoptosis, while the caspase- 9 inhibitor z-LEHD-fmk caused weaker but statistically significant inhibition. At the same time, the caspase-4 inhibitor z-LEVD-fmk had little effect on apoptosis. These results indicated that the combined treatment with andrographolide and rhTRAIL causes apoptosis primarily by stimulating the extrinsic apoptotic pathway (caspase-8/caspase-3) and, to a lesser extent, via activation of mitochondria-linked caspase-9. Pro-apoptotic effects of the combined treatment with andrographolide and rhTRAIL did not appear to involve the endoplasmic reticulum stress-associated apoptotic cascade in this system. The TRAIL-sensitizing effect of andrographolide was examined in TRAIL-resistant AGS cells by assessing actual activation of caspases during induction of apoptosis by the combined treatment. In response to the treatment with 5 and $10 \mathrm{ng} / \mathrm{ml} \mathrm{rhTR}$ AIL, activity levels of caspase-3, caspase- 8 and caspase-9 slightly increased. Treatment of AGS cells with $10 \mu \mathrm{M}$ andrographolide alone did not induce any increase in activity of these enzymes. However, the combined treatment with andrographolide and rhTRAIL enhanced activity of these three caspases (Fig. 4B). To determine the identity of the caspase cascades involved, several selective inhibitors of corresponding enzymes in AGS cells were used. It was revealed that z-IETD-fmk significantly blocked activity levels of caspase-9 $(\mathrm{P}=0.035)$ and caspase- $3(\mathrm{P}=0.012)$, whereas z-DEVD-fmk partially inhibited activation of caspase-8. At the same time, z-LEHD-fmk had little effect on activation of caspase- 8 and only partially decreased caspase- 3 activity (Fig. 4C). Collectively, these results indicated that the combined administration of andrographolide with rhTRAIL induces caspase- 8 activation upstream of caspase- 9 and caspase-3.

DR5 signaling is essential for andrographolide-mediated sensitization to the action of rhTRAIL. The extrinsic apoptotic pathway appeared to be important in mediating apoptosis caused by the combined treatment with andrographolide and rhTRAIL, as demonstrated by the major role of the caspase-8/caspase-3 axis in this process. It was observed that incubation with andrographolide led to increased expression levels of DR4 and DR5, the receptors mediating TRAIL-induced apoptosis in GC cells. Thus, the RNA interference approach was performed to confirm the role of DR4 and DR5 in sensitization to the effects of rhTRAIL caused by andrographolide. AGS cells transfected with scrambled control RNA, DR4 siRNA or DR5 siRNA were incubated with andrographolide and rhTRAIL, and apoptosis was then assessed by evaluating apoptotic body formation. Knockdown of DR5 significantly reduced the extent of apoptosis $(\mathrm{P}=0.028)$. By contrast, DR4 knockdown failed to prevent apoptosis induced by the combined treatment with andrographolide and rhTRAIL (Fig. 5). This may be explained by the evidence that the concentration of andrographolide used for the sensitizing activity was reduced compared with the concentration required for efficient DR4 induction. Thus, DR5 appears to perform a more important role compared with DR4 in mediating andrographolide-induced sensitization of AGS cells to the action of rhTRAIL. However, activation of multiple signaling apoptotic pathways cannot be ruled out, since apoptosis was not completely rescued by DR5 knockdown.

ROS is involved in andrographolide-induced sensitization to effects of rhTRAIL through potentiation of DR5 expression. Oxidative stress by chemopreventive agents, including curcumin and casticin, has been implicated in DR5 upregulation and apoptosis (35-37). Furthermore, numerous natural antitumor compounds have been reported to induce ROS production $(35,37)$. The present study explored whether ROS is involved in apoptosis triggered by the combined action of andrographolide and rhTRAIL by examining the effects of various antioxidants. The general ROS scavenger $\mathrm{N}$-acetyl cysteine (NAC) profoundly suppressed apoptosis and activation of caspases following the combination treatment, whereas application of catalase had a weaker, but 
A

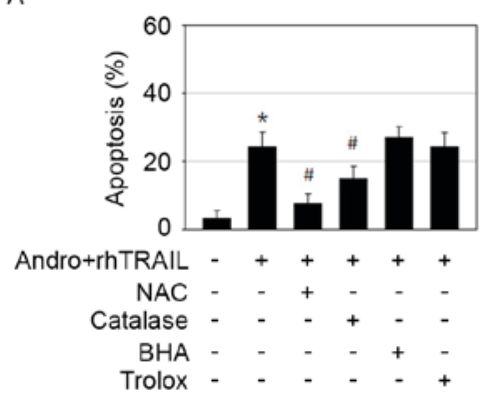

C

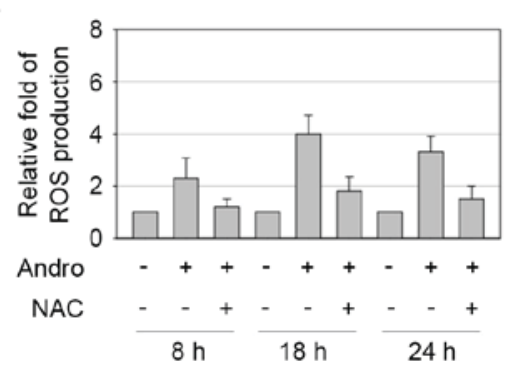

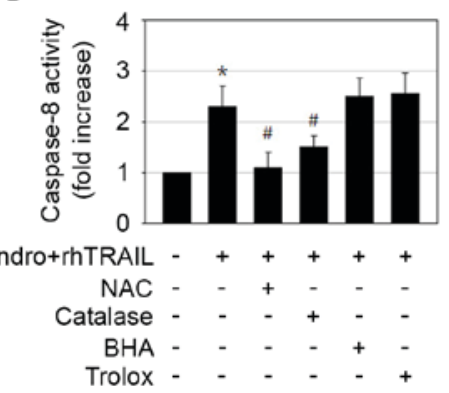

D

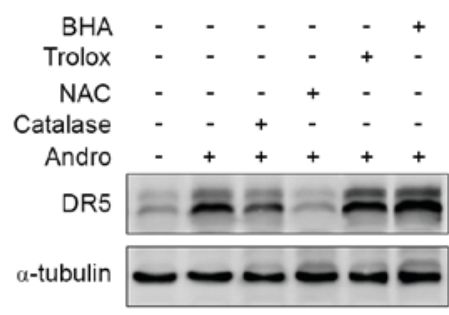

Figure 6. Andrographolide-induced ROS generation induces DR5 expression and is important for rhTRAIL-sensitizing effect. (A and B) AGS cells were treated with a combination of $15 \mu \mathrm{M}$ andrographolide and $10 \mathrm{ng} / \mathrm{ml}$ rhTRAIL in the absence or presence of $5 \mathrm{mM}$ NAC, $500 \mathrm{U}$ catalase, $50 \mu \mathrm{M}$ BHA and $50 \mu \mathrm{M}$ trolox for $48 \mathrm{~h}$. The treated cells were (A) stained with Hoechst 33342 to allow detection of apoptotic cells or (B) subjected to caspase- 8 and -3 activity assay. ${ }^{*} \mathrm{P}<0.05$ vs. control; ${ }^{*} \mathrm{P}<0.05$ vs. andrographolide and rhTRAIL-treated cells. (C) Cells treated with $15 \mu \mathrm{M}$ andrographolide in the presence or absence of $5 \mathrm{mM}$ NAC were analyzed for ROS generation using DCFH-DA at 8, 18 and $24 \mathrm{~h}$ post-incubation. (D) Cells exposed to $15 \mu \mathrm{M}$ andrographolide in the absence or presence of $5 \mathrm{mM}$ NAC, $500 \mathrm{U}$ catalase, $50 \mu \mathrm{M}$ BHA and $50 \mu \mathrm{M}$ trolox for $48 \mathrm{~h}$ were analyzed by immunoblotting. ROS, reactive oxygen species; DR5, tumor necrosis factor-related apoptosis-inducing ligand-receptor 2; rhTRAIL, recombinant human tumor necrosis factor-related apoptosis-inducing ligand; NAC, N-acetyl cysteine; BHA, butylated hydroxyanisole; Andro, andrographolide.

statistically significant, inhibitory effect (Fig. 6A and B). However, treatments with the superoxide anion scavenger butylated hydroxyanisole (BHA) or the lipid peroxidation inhibitor trolox had no effect (Fig. 6A and B). Based on these results, ROS, including hydrogen peroxide but not superoxide anion or superoxide radicals, appear to possess a critical role in apoptosis induced by the combined treatment with andrographolide and rhTRAIL. As determined by the dichloro-dihydro-fluorescein diacetate assay, exposure of AGS cells to andrographolide significantly increased ROS production, which may be reduced by application of NAC (Fig. 6C). The effect of antioxidants on the increase of DR5 expression induced by andrographolide was also examined. Similar to its inhibitory effect on apoptosis induction, NAC almost completely blocked induction of DR5 expression (Fig. 6D). BHA and trolox had no effect on DR5 induction, while catalase caused only a partial decrease in DR5 expression (Fig. 6D). Therefore, induction of oxidative stress by andrographolide may be the essential mechanism for DR5 induction and sensitization to the pro-apoptotic effects of rhTRAIL in GCs.

In conclusion, the present study revealed a possible role for andrographolide as a sensitizer of GC cells to the action of TRAIL. Based on the present results, co-application of these drugs may improve therapeutic efficacy of GC treatment, although additional clinical studies are required.

\section{Acknowledgements}

The present study was supported by the Basic Science Research Program through the National Research Foundation of Korea funded by the Ministry of Education, Science and Technology (grant no. NRF-2011-0014540). The authors thank Professor Tae-Hyoung Kim for supplying rhTRAIL and Ms. Jeong-Eun Choi for her technical assistance.

\section{References}

1. Piazuelo MB and Correa P: Gastric cáncer: Overview. Colomb Med (Cali) 44: 192-201, 2013.

2. Wagner AD, Unverzagt S, Grothe W, Kleber G, Grothey A, Haerting J and Fleig WE: Chemotherapy for advanced gastric cancer. Cochrane Database Syst Rev CD004064, 2010.

3. Van Cutsem E, Haller D and Ohtsu A: The role of chemotherapy in the current treatment of gastric cancer. Gastric Cancer 5 (Suppl 1): $17-22,2002$

4. Gura T: How TRAIL kills cancer cells, but not normal cells. Science 277: 768, 1997.

5. Baker SJ and Reddy EP: Modulation of life and death by the TNF receptor superfamily. Oncogene 17: 3261-3270, 1998.

6. Ashkenazi A: Targeting death and decoy receptors of the tumour-necrosis factor superfamily. Nat Rev Cancer 2: 420-430, 2002.

7. Srivastava RK: TRAIL/Apo-2L: Mechanisms and clinical applications in cancer. Neoplasia 3: 535-546, 2001.

8. Prasad S, Yadav VR, Kannappan R and Aggarwal BB: Ursolic acid, a pentacyclin triterpene, potentiates TRAIL-induced apoptosis through p53-independent up-regulation of death receptors: Evidence for the role of reactive oxygen species and JNK. J Biol Chem 286: 5546-5557, 2011.

9. Siddiqui IA, Malik A, Adhami VM, Asim M, Hafeez BB, Sarfaraz S and Mukhtar H: Green tea polyphenol EGCG sensitizes human prostate carcinoma LNCaP cells to TRAIL-mediated apoptosis and synergistically inhibits biomarkers associated with angiogenesis and metastasis. Oncogene 27: 2055-2063, 2008.

10. Szliszka E and Krol W: The role of dietary polyphenols in tumor necrosis factor-related apoptosis inducing ligand (TRAIL)-induced apoptosis for cancer chemoprevention. Eur J Cancer Prev 20: 63-69, 2011. 
11. Xia YF, Ye BQ, Li YD, Wang JG, He XJ,Lin X, Yao X, Ma D, Slungaard A, Hebbel RP, et al: Andrographolide attenuates inflammation by inhibition of NF-kappa B activation through covalent modification of reduced cysteine 62 of p50. J Immunol 173: 4207-4217, 2004

12. Wang YJ, Wang JT, Fan QX and Geng JG: Andrographolide inhibits NF-kappaBeta activation and attenuates neointimal hyperplasia in arterial restenosis. Cell Res 17: 933-941, 2007.

13. Zhang QQ, Zhou DL, Ding Y, Liu HY, Lei Y, Fang HY, Gu QL, He XD, Qi CL, Yang Y, et al: Andrographolide inhibits melanoma tumor growth by inactivating the TLR4/NF- $\mathrm{BB}$ signaling pathway. Melanoma Res 24: 545-555, 2014.

14. Zhang QQ, Ding Y, Lei Y, Qi CL, He XD, Lan T, Li JC, Gong P, Yang X, Geng JG and Wang LJ: Andrographolide suppress tumor growth by inhibiting TLR4/NF- $\mathrm{B}$ signaling activation in insulinoma. Int J Biol Sci 10: 404-414, 2014.

15. Liu SH, Lin CH, Liang FP, Chen PF, Kuo CD, Alam MM, Maiti B, Hung SK, Chi CW, Sun CM and Fu SL: Andrographolide downregulates the $\mathrm{v}-\mathrm{Src}$ and $\mathrm{Bcr}-\mathrm{Abl}$ oncoproteins and induces Hsp90 cleavage in the ROS-dependent suppression of cancer malignancy. Biochem Pharmacol 87: 229-242, 2014.

16. Shen K, Ji L, Lu B, Xu C, Gong C, Morahan G and Wang Z: Andrographolide inhibits tumor angiogenesis via blocking VEGFA/VEGFR2-MAPKs signaling cascade. Chem Biol Interact 218: 99-106, 2014

17. Yang SH, Wang SM, Syu JP, Chen Y, Wang SD, Peng YS, Kuo MF and Kung HN: Andrographolide induces apoptosis of C6 glioma cells via the ERK-p53-caspase 7-PARP pathway. Biomed Res Int 2014: 312847, 2014

18. Li J, Zhang C, Jiang $\mathrm{H}$ and Cheng J: Andrographolide inhibits hypoxia-inducible factor-1 through phosphatidylinositol 3-kinase/AKT pathway and suppresses breast cancer growth. Onco Targets Ther 8: 427-435, 2015.

19. Nateewattana J, Dutta S, Reabroi S, Saeeng R, Kasemsook S, Chairoungdua A, Weerachayaphorn J, Wongkham S and Piyachaturawat P: Induction of apoptosis in cholangiocarcinoma by an andrographolide analogue is mediated through topoisomerase II alpha inhibition. Eur J Pharmacol 723: 148-155, 2014.

20. Lu CY, Yang YC, Li CC, Liu KL, Lii CK and Chen HW: Andrographolide inhibits TNF $\alpha$-induced ICAM-1 expression via suppression of NADPH oxidase activation and induction of HO-1 and GCLM expression through the PI3K/Akt/Nrf2 and PI3K/Akt/AP-1 pathways in human endothelial cells. Biochem Pharmacol 91: 40-50, 2014.

21. Zhou J, Ong CN, Hur GM and Shen HM: Inhibition of the JAK-STAT3 pathway by andrographolide enhances chemosensitivity of cancer cells to doxorubicin. Biochem Pharmacol 79: $1242-1250,2010$

22. Lin HH, Shi MD, Tseng HC and Chen JH: Andrographolide sensitizes the cytotoxicity of human colorectal carcinoma cells toward cisplatin via enhancing apoptosis pathways in vitro and in vivo. Toxicol Sci 139: 108-120, 2014.

23. Shin JN, Park SY, Cha JH, Park JY, Lee BR, Jung SA, Lee ST, Yun CW, Seol DW and Kim TH: Generation of a novel proform of tumor necrosis factor-related apoptosis-inducing ligand (TRAIL) protein that can be reactivated by matrix metalloproteinases. Exp Cell Res 312: 3892-3898, 2006.
24. Laemmli UK: Cleavage of structural proteins during the assembly of the head of bacteriophage T4. Nature 227: 680-685, 1970.

25. Franken NA, Rodermond HM, Stap J, Haveman J and van Bree C: Clonogenic assay of cells in vitro. Nat Protoc 1: 2315-2319, 2006

26. Rafehi H, Orlowski C, Georgiadis GT, Ververis K, El-Osta A and Karagiannis TC: Clonogenic assay: Adherent cells. J Vis Exp pii: 2573, 2011

27. el-Deiry WS, Harper JW, O'Connor PM, Velculescu VE, Canman CE, Jackman J, Pietenpol JA, Burrell M, Hill DE, Wang Y, et al: WAF1/CIP1 is induced in p53-mediated G1 arrest and apoptosis. Cancer Res 54: 1169-1174, 1994.

28. Wu GS, Burns TF, McDonald ER III, JiangW, Meng R, Krantz ID, Kao G, Gan DD, Zhou JY, Muschel R, et al: KILLER/DR5 is a DNA damage-inducible p53-regulated death receptor gene. Nat Genet 17: 141-143, 1997.

29. Sheikh MS, Burns TF, Huang Y, Wu GS, Amundson $S$, Brooks KS, Fornace AJ Jr and el-Deiry WS: p53-dependent and -independent regulation of the death receptor KILLER/DR5 gene expression in response to genotoxic stress and tumor necrosis factor alpha. Cancer Res 58: 1593-1598, 1998.

30. Park JG, Yang HK, Kim WH, Chung JK, Kang MS, Lee JH, Oh JH, Park HS, Yeo KS, Kang SH, et al: Establishment and characterization of human gastric carcinoma cell lines. Int J Cancer 70: 443-449, 1997.

31. Ruiz-González R, Milán P, Bresolí-Obach R, Stockert JC, Villanueva A, Cañete M and Nonell S: Photodynamic Synergistic Effect of Pheophorbide a and Doxorubicin in Combined Treatment against Tumoral Cells. Cancers (Basel) 9: pii: E18, 2017.

32. Jerzak KJ, Berry S, Ko YJ, Earle C and Chan KK: Cetuximab plus Irinotecan versus Panitumumab in Patients with refractory metastatic colorectal cancer in Ontario, Canada. Int $\mathrm{J}$ Cancer 2017 (Epub ahead of print).

33. Zhang W and Tung CH: Cisplatin Cross-linked Multifunctional Nanodrugplexes for Combination Therapy. ACS Appl Mater Interfaces 2017 (Epub ahead of print).

34. Zhang H, Dong L, Chen Q, Kong L, Meng B, Wang H, Fu K, Wang X, Pan-Hammarström Q, Wang P and Wang X: Synergistic antitumor effect of histone deacetylase inhibitor and Doxorubicin in peripheral T-cell lymphoma. Leuk Res 56: 29-35, 2017.

35. Jung EM, Lim JH, Lee TJ, Park JW, Choi KS and Kwon TK: Curcumin sensitizes tumor necrosis factor-related apoptosis-inducing ligand (TRAIL)-induced apoptosis through reactive oxygen species-mediated upregulation of death receptor 5 (DR5). Carcinogenesis 26: 1905-1913, 2005.

36. Tang SY, Zhong MZ, Yuan GJ, Hou SP, Yin LL, Jiang H and Yu Z: Casticin, a flavonoid, potentiates TRAIL-induced apoptosis through modulation of anti-apoptotic proteins and death receptor 5 in colon cancer cells. Oncol Rep 29: 474-480, 2013.

37. Zhou Y, Tian L, Long L, Quan M, Liu F and Cao J: Casticin potentiates TRAIL-induced apoptosis of gastric cancer cells through endoplasmic reticulum stress. PLoS One 8: e58855, 2013. 